BaILey, L. (1957) J. gen. Microbiol. 17, 39-48

\title{
The Isolation and Gultural Characteristics of Strepto- coccus pluton and further Observations on Bacterium eurydice
}

\author{
By L. BAILEY \\ Bee Department, Rothamsted Experimental Station, Harpenden, Hertfordshire
}

\begin{abstract}
SUMMARY: An account is given of the development of a reliable method for the isolation of Streptococcus pluton (Bacillus pluton White), an organism associated with European foul-brood disease of the larval honeybee. S. pluton, isolated as an anaerobe, may be trained to grow as an aerobe in rod form. Its principal anaerobic growth requirements are a low molar ratio of $\mathrm{Na}: \mathrm{K}$, high inorganic phosphate concentration, glucose or fructose, and undetermined factors provided by yeast extract. Peptones are harmful to growth. Aerobic growth has no very critical requirements other than glucose, fructose or sucrose. Bacterium eurydice White which, together with $S$. pluton, causes European foul-brood disease grows well anaerobically on a yeast extract + glucose + fructose medium; either sugar alone supports only feeble anaerobic growth. Anaerobic growth of B. eurydice is also accelerated by a low molar ratio of $\mathrm{Na}: \mathrm{K}$ and is inhibited by peptones. S. pluton and $B$. eurydice appear to be separate organisms; no evidence has been obtained to support claims by previous workers that $S$. pluton is a variant of $B$. eurydice.
\end{abstract}

It has recently been established (Bailey, 1956) that Streptococcus pluton (Bacillus pluton White) is a distinct organism which, together with Bacterium eurydice White, causes European foul-brood disease of the larval honeybee. Other bacteria commonly associated with diseased or dead larvae are Streptococcus liquefaciens Sternberg (S. apis Maassen) and Bacillus alvei Cheshire \& Cheyne. All four bacteria, either separately or in combination, have at one time or another been considered the cause of the disease. Streptococcus pluton has also been thought to be a variant of Bacterium eurydice (Burri, 1943) or of Bacillus alvei (Lochhead, 1928). A summary of these previous views has been given by N. R. Smith in Bergey's Manual (1948) and by Steinhaus (1949). The following is an account of the isolation of $S$. pluton and of some of its cultural characteristics, together with some new observations on Bacterium eurydice. The relationships between the cultural characters of these two organisms and their development in the honeybee larva are discussed.

\section{METHODS}

The diseased larvae were obtained from colonies of honeybees which were affected to various degrees with European foul-brood disease. The colonies had been kept at an isolated site near Rothamsted Experimental Station, Harpenden, since May 1954. The disease has occurred annually in all these bee colonies and has been allowed to run its normal course without remedial treatment. The symptoms and general nature of European foul-brood disease 
described fully by White (1920) were found identical with those observed in the infected colonies studied at Rothamsted.

Larvae, from which isolates were to be prepared, were selected carefully. For the attempts in 1954, larvae were chosen which appeared to be healthy but which were surrounded by others in all stages of the disease. In this way it was hoped that the chances of obtaining pure cultures of Streptococcus pluton would be increased and that other bacteria to be found in moribund larvae would be avoided. For the subsequent attempts larvae which were showing initial symptoms of the disease were selected; they were slightly displaced in their honeycomb cells or appeared faintly yellow in bright light; but otherwise they had the turgid and glistening appearance of healthy larvae.

The larvae selected were dissected on sterile microscope slides. The cuticle was grasped half way down the length of the body with two pairs of sterile forceps which were then drawn apart. In this way the cuticle was removed, leaving the mid-gut in a pool of body fluid on the slide. A loop of the mid-gut contents was streaked on a plate of the medium. Except where indicated, cultures were incubated anaerobically at $c . \mathbf{3 3}^{\circ}$ in McIntosh \& Fildes jars which contained hydrogen $95 \%(\mathrm{v} / \mathrm{v})+5 \%(\mathrm{v} / \mathrm{v}) \mathrm{CO}_{2}$. B.D.H. capillator indicators (British Drug Houses Ltd.) were used to determine the $\mathrm{pH}$ values of fluids.

\section{RESULTS}

The isolation of Streptococcus pluton

Isolates of an oval Gram-positive coccus which seemed likely to be Streptococcus pluton were first made on glucose nutrient agar in 1954 by Professor L. P. Garrod (St Bartholomew's Hospital), who was collaborating in the work at this time (Rep. Roth. Exp. Sta. 1954); but the growth of this organism was very feeble and it often appeared to degenerate into a variety of pleomorphic forms. It appeared to be an anaerobe, and yeast extract was beneficial to growth. Several attempts were made to infect small colonies of bees with cultures prepared by Professor Garrod, but the disease did not appear. On one occasion, however, the mid-gut of one larva was seen to contain clumps of Grampositive cocci. Their appearance seemed identical with that of $S$. pluton in naturally-infected larvae. The healthy bees had come from apiaries known to have been free from the disease since 1946 and it was considered very likely therefore that Professor Garrod's isolate was $S$. pluton, but that cultural conditions were unsatisfactory and that virulence had probably been lost. Attempts to repeat or improve the tests in the spring of 1955 were unsuccessful. Efforts were made in September 1955 to re-isolate the organism on different media. The first medium tried was modified from one which had been found suitable for the isolation of Bacillus larvae White, which causes American foul-brood of the honeybee larvae. It was made up as follows: $10 \mathrm{~g}$. soluble starch; 10 g. glucose; 5 g. Neopeptone (Difco); 5 g. yeast extract (Difco); $1.36 \mathrm{~g} . \mathrm{KH}_{2} \mathrm{PO}_{4} ; 20 \mathrm{~g}$. agar; diluted to $1000 \mathrm{ml}$. with distilled water. The $\mathrm{pH}$ value was adjusted to $6 \cdot 8$ with concentrated $\mathrm{KOH}$ and the medium was 
sterilized by steaming at $100^{\circ}$ for $20 \mathrm{~min}$. on 3 successive days. It will be referred to below as medium I. After one day of incubation there was a slight growth, at the start of the streak, of confluent transparent colonies composed of short rods. After 6 days white colonies about $\mathbf{0 . 2 5} \mathrm{mm}$. diameter were observed to be growing on the confluent colonies. The white colonies were composed of lanceolate streptococci in chains of various lengths. These organisms were Gram-positive and seemed morphologically identical with S. pluton. Attempts to subculture these bacteria met with variable success and usually failed on agar plates of medium $I$; cultures in liquid medium I were more reliable, although growth was only slight. There was an initial growth of thin rods followed by the development of streptococci after about 2 days; acid was formed and the $\mathrm{pH}$ value consistently fell to $4 \cdot 8$. At this stage it was believed that the rods were an early phase of the streptococci, as growth of the latter occurred only on the colonies of the rods on agar of medium I and the rods resembled the pleomorphic forms which Professor Garrod had previously isolated. However, since acid was formed, it seems more likely that the rods were Bacterium eurydice (see below). Only one more isolate of the streptococcus, together with the thin rods, was made in 1955. More isolates could not be prepared after the middle of September as the disease had died out, as is usual each year at this time.

Attempts to improve the medium were begun; tests were done with subcultures from the two isolates made in 1955 , described above. It was found that a tenfold increase of potassium phosphate resulted in a heavy growth of the streptococci and that starch was unnecessary.

For the rest of the winter period, before new isolates could be made again in the spring of 1956, the following medium was used: $10 \mathrm{~g}$. glucose; $5 \mathrm{~g}$. Neopeptone (Difco); 5 g. yeast extract (Difco); 13.6 g. $\mathrm{KH}_{2} \mathrm{PO}_{4} ; 20$ g. agar; diluted to $1000 \mathrm{ml}$. with distilled water. The $\mathrm{pH}$ value was adjusted to $6 \cdot 8$ and sterilization was by steaming as before. This medium will be referred to below as medium II.

Growth of the streptococcus on agar of medium II was reliable and was in pure culture; the rods had been lost.

Home-made yeast extract, equivalent in growth effect to the Difco product, was prepared in two ways:

(1) $100 \mathrm{~g}$. of baker's yeast were added to $450 \mathrm{~g}$. water and then steamed for $1 \mathrm{hr}$.; after allowing solids to settle the supernatant fluid was decanted and filtered. The solid content of the extract was about $1 \cdot 2 \%(\mathrm{w} / \mathrm{v})$.

(2) $100 \mathrm{~g}$. baker's yeast was allowed to autolyse at $50^{\circ}$ for $24 \mathrm{hr}$. or until liquid, and then diluted with water to $400 \mathrm{ml}$. After steaming for $30 \mathrm{~min}$. the solid matter was allowed to settle and the supernatant fluid decanted and filtered; the solid content of the extract was about $3.5 \%(w / v)$.

The following peptones were tried instead of Neopeptone (Difco): peptone, Tryptone, Tryptose, Proteose-peptone (Bacto); peptone, Tryptone (Oxoid). None of these improved growth and Bacto-peptone was distinctly inhibitory. Some growth occurred when Neopeptone was entirely replaced by yeast extract but the growth seemed feebler. 
When the disease reappeared in the spring of 1956 attempts were made to isolate Streptococcus pluton on medium II. A growth of rods of various sizes was obtained, some of which were probably Bacterium eurydice and the rest pleomorphic forms of Streptococcus pluton, but it was not found possible to isolate the streptococcal form. As $\boldsymbol{S}$. pluton had grown on agar of medium II without Neopeptone further attempts were made with this simpler medium. All attempts were now successful, and two distinct colony forms were always isolated from diseased larvae. The first appeared after incubation for $24 \mathrm{hr}$. as transparent bluish grey colonies, light brown by transmitted light and composed of thin rods. These were identified as $B$. eurydice, the cultural details agreeing with those given by Gubler (1954). Only feeble growth occurred. Dense white colonies of $S$. pluton became visible after about 2 days. It was not found possible to isolate $S$. pluton on medium II when it contained any kind of peptone. $S$. pluton could be trained to grow in the presence of Neopeptone and it then grew a little more profusely, but it seemed preferable not to use this peptone. The following medium was therefore used: $10 \mathrm{~g}$. glucose, $10 \mathrm{~g}$. yeast extract (Difco), $13 \cdot 6 \mathrm{~g}$. $\mathrm{KH}_{2} \mathrm{PO}_{4}, 20 \mathrm{~g}$. agar, made up to $1000 \mathrm{ml}$. with distilled water. The $\mathrm{pH}$ value of this medium was adjusted to pH 6.6 with concentrated $\mathrm{KOH}$ and it was sterilized by steaming. It will be referred to as medium III.

\section{Cultural characteristics of Streptococcus pluton}

The cultural characters of the streptococci isolated in 1955 and 1956 from diseased larvae were determined by the use of media II or III as indicated below. Other than the unsuitability of medium II for the initial isolation of Streptococcus pluton no results were obtained with it which conflicted with those obtained later with medium III.

Colony characteristics. Growth on agar (media II and III) produced round raised colonies which were 1 or $1.5 \mathrm{~mm}$. in diameter, granular and pearly white by reflected light, and nearly opaque and brownish by transmitted light.

Growth in liquid media. A flocculent growth which appeared at the bottom of the tube (media II and III) about 2 days after inoculation settled to give a dense white deposit of streptococci.

Acid formation. The formation of acid was not detectable (media II and III). Carbohydrate dissimilation. The following carbohydrates were used: glucose, fructose, sucrose, galactose, lactose, maltose, raffinose, rhamnose, mannitol, sorbitol, inositol, d-xylose, glycerol and starch. Only glucose and fructose supported growth (medium II).

Optimum temperature. Growth, which occurred at $20^{\circ}, 25^{\circ}, 30^{\circ}, 35^{\circ}, 40^{\circ}$, and $45^{\circ}$, was best at $35^{\circ}$ (medium II).

Optimum $\mathrm{pH}$ value. Best growth occurred at $\mathrm{pH} 6 \cdot 5-6 \cdot 6$; reasonable growth

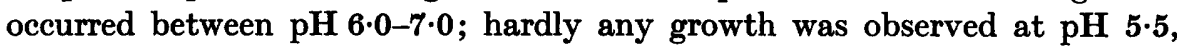
even after prolonged incubation (medium III).

Effect of $\mathrm{CO}_{2}$. The presence of $\mathrm{CO}_{2}$ in the gas phase in concentrations from 1 to $100 \%(\mathrm{v} / \mathrm{v})$ markedly stimulated growth; the concentration of $\mathrm{CO}_{2}$ did not seem to be critical (medium II). 
Effect of the ratio of $\mathrm{Na}: \mathrm{K}$. No growth occurred when the potassium phosphate was replaced with an equimolar concentration of sodium phosphate. Until the molar ratio of $\mathrm{Na}: \mathrm{K}$ was 1 or less severe inhibition of growth was obvious (medium II).

Phosphate requirement. Decrease of the concentration of potassium phosphate by half usually made no difference to growth, but occasionally it was feebler. Further decrease in phosphate concentration markedly diminished growth (media II and III).

Effect of citrate. Potassium citrate buffer $(0.01 \mathrm{M}$ and $0.1 \mathrm{M})$ was tried instead of phosphate; no growth occurred. Addition of potassium phosphate did not restore growth; but the use of magnesium citrate instead of potassium citrate restored growth when phosphate was present (medium III).

Effect of different sterilization techniques. Growth occurred after medium III had been autoclaved at $5 \mathrm{lb} . / \mathrm{sq}$. in. $\left(108^{\circ}\right)$ or $15 \mathrm{lb}$./sq.in. $\left(121^{\circ}\right)$, but it often seemed inferior to that on the steamed medium; a freshly prepared steamed medium was best. Heat-sterilized media with the sugar added afterwards often did not support any growth. Media which had been sterilized by filtration through a Seitz filter or sintered glass did not support any growth (medium III).

Effect of oxygen. During the development of medium II growth sometimes occurred in broths of this medium enclosed with air in screw-capped bottles. The initial growth was of rods which seemed larger than before and more abundant. No acid was formed; at first this was attributed to the high concentration of phosphate buffer. However, the rods seemed to degenerate when Streptococcus pluton began to appear; they were not the same as before, i.e. not Bacterium eurydice but were $S$. pluton which had been trained to grow at high oxygen tensions; $B$. eurydice had been lost. In anaerobic culture the streptococci were now the first and only forms which appeared (medium II). It was found later that $S$. pluton could be trained to grow in high oxygen tensions fairly regularly by subcultivation in broths of medium III enclosed with air in screw-capped bottles. It sometimes took 7 days or more before an inoculum from an anaerobic culture began to grow, but it would then grow luxuriantly in further subculture as an aerobe in rod form.

A luxuriant aerobic growth of these rods was obtained on agar(media II and III). The colonies were flat, up to $3 \mathrm{~mm}$. in diameter, fawn-grey by reflected light, and granular and light brown by transmitted light. They had a slightly undulate edge and surface and were composed of Gram-variable rods of varying thickness and length (Pl. 1, fig. 4). The colonies emulsified easily in water, unlike those of Bacterium eurydice which are very water-repellant. When grown on agar (media II and III) enclosed with air in a screw-capped bottle the colonies gradually grew transparent and collapsed. As they dwindled, white pin-point colonies appeared which grew to about $1 \mathrm{~mm}$. in diameter; these were colonies of the streptococcal form. The aerobically-trained form subcultured anaerobically in the streptococcal form provided it had been converted into the anaerobic form in each subculture; when it was subcultured under fully aerobic conditions the ability to grow anaerobically was lost, 
sometimes even after the first subculture. When the streptococcal form from an initially aerobic culture was repeatedly subcultured anaerobically it lost the ability to grow aerobically (usually after two or three subcultures) but could be retrained to do so (medium III). The aerobic form produced an atmosphere rich in $\mathrm{CO}_{2}$; this was shown by drawing the atmosphere from a culture grown in a screw-capped bottle through lime-water, which rapidly became very turbid (media II and III). No acid was formed (media II and III). The aerobic form had no very critical nutrient requirements; citrate did not inhibit growth nor did excess of sodium over potassium (media II and III). Ordinary laboratory media supported growth provided glucose, fructose or sucrose were available. It was not found possible to cultivate the aerobic form directly from infected larvae (media II and III).

Streptococcus pluton which had not been trained to grow aerobically would nevertheless grow well in atmospheres containing $0 \cdot 4 \%(\mathrm{v} / \mathrm{v}) \mathrm{O}_{2}$, as found by incubating subcultures in desiccators which had been evacuated to the necessary pressure and then filled with hydrogen containing $5 \%(\mathrm{v} / \mathrm{v}) \mathrm{CO}_{2}$; but distinct inhibition of growth occurred in $1 \%(\mathrm{v} / \mathrm{v}) \mathrm{O}_{2}$ and cocci were poorly differentiated in the chains, which became rod-like (medium III) (Pl. 1, fig. 3).

Catalase production. Aerobic cultures had a high catalase activity. Tubes containing slopes of aerobic cultures were filled with hydrogen peroxide (20 vol.) and inverted over water; the tubes were completely filled with oxygen within a few seconds. Anaerobic cultures, tested in the same way, showed no catalase activity (medium III).

Staining properties. The organisms were usually Gram-positive, but a variable proportion of Gram-negative organisms were always present (media II and III). Aerobic cultures which had converted to streptococcal (anaerobic) forms in closed bottles usually produced clusters of Gram-positive cocci set in a matrix of Gram-negative material; their appearance then resembled most closely that of Streptococcus pluton from infected larvae (media II and III). The cocci, which were highly refractile in watery suspension, had thick cell walls which stained well by Robinow's tannic acid + crystal violet method (medium II) (Pl. 1, fig. 6). This has been shown in $S$. pluton from infected larvae (Gubler, 1954).

Maintenance of viability. Cultures kept in an anaerobic atmosphere at room temperatures on agar slopes (medium II) subcultured readily after 6 months.

\section{Cultural characteristics of Bacterium eurydice}

These were all determined on Medium III, using as stock cultures organisms isolated from diseased larvae in 1956 on medium III.

Growth on agar. Colonies were transparent, bluish-grey by reflected light and light brown by transmitted light. As described by Gubler (1954) they did not emulsify readily in water. The rods were variable morphologically; often semicircular in early culture they usually developed as straight rods of varying lengths and were about half as thick as Streptococcus pluton; there were occasional chains of cocco-bacillary forms. 
A second distinct strain was isolated from diseased larvae on medium III; it had rods about as thick as Streptococcus pluton and grew in colonies which were denser than those of the other strain of Bacterium eurydice but in all the other cultural details listed below the two strains were identical. The occasional chains of cocco-bacilli sometimes bore a superficial resemblance to $S$. pluton, but there was never any evidence of dissociation of these cultures of B. eurydice into a form which could be grown with the cultural characteristics of S. pluton.

Acid formation. The formation of acid by Bacterium eurydice has already been described (Gubler, 1954). In this work the growth of $B$. eurydice decreased the $\mathrm{pH}$ value constantly to $4 \cdot 8$, whether growth occurred aerobically or anaerobically.

Effect of glucose and fructose. Glucose or fructose seemed essential for good growth of Bacterium eurydice (Gubler, 1954). During experiments upon the effect of sterilizing agents upon mixed cultures of $B$. eurydice and Streptococcus pluton in suspension in honey it was seen that a very vigorous growth of $B$. eurydice occurred anaerobically; $S$. pluton did not grow. Further investigation showed that the vigorous growth was caused by the honey unavoidably included in the medium when the suspensions had been plated. It was then found that vigorous anaerobic growth of $B$. eurydice occurred when glucose + fructose were included in the medium; either sugar separately had no stimulating effect at any concentration. The $\mathrm{pH}$ value of the medium which contained glucose + fructose rapidly fell to about 4.2 when supporting a culture of $B$. eurydice; it was difficult, for this reason, to obtain growth of $S$. pluton from a mixed culture. (The growth of pure cultures of $S$. pluton is the same on media containing glucose or fructose or both).

Effect of citrate. Aerobic growth of Bacterium eurydice was not affected, but anaerobic growth was completely inhibited, by $1 \%(w / v)$ potassium citrate. The equivalent concentration of magnesium citrate did not inhibit growth.

Effect of the molar ratio of $\mathrm{Na}: \mathrm{K}$. Anaerobic growth was delayed by about $24 \mathrm{hr}$. when potassium phosphate was replaced in the medium by an equimolar concentration of sodium phosphate.

Effect of peptones. Anaerobic growth was slightly inhibited by peptones.

Effect of sterilization techniques. Anaerobic growth was delayed in media which had been autoclaved at $15 \mathrm{lb} . / \mathrm{sq} . \mathrm{in} .\left(121^{\circ}\right)$; it was depressed in Seitzfiltered media.

Catalase activity. Aerobic cultures of Bacterium eurydice slowly decomposed hydrogen peroxide; anaerobic cultures did not.

Maintenance of viability. Cultures of Bacterium eurydice on agar or in broth kept at room temperature, lost viability after about three weeks.

\section{Growth of Streptococcus pluton and Bacterium eurydice in mixed culture}

The two organisms readily grew together ( $\mathrm{Pl}$. 1, fig. 2), and the colonies of Streptococcus pluton were then often seen growing within the more transparent colonies of Bacterium eurydice. When mixed cultures were grown enclosed with air in sealed bottles the initial growth of B. eurydice rapidly exhausted the 
oxygen sufficiently to permit growth of $S$. pluton. Both organisms also grew in mixed culture anaerobically, but then the growth of $B$. eurydice was feeble.

Mixed cultures were freeze-dried; both organisms subcultured readily from the dried preparations after 17 weeks.

\section{DISCUSSION}

Some ability to grow aerobically seems to be a normal faculty of Streptococcus pluton; the luxuriant aerobic growth which was obtained was probably the result of exaggeration of this faculty by training. A slight catalase activity by the anaerobic form would destroy a small amount of hydrogen peroxide which may be formed in very low oxygen tensions; but growth could be inhibited by excessive formation of hydrogen peroxide in aerobic conditions. This inhibition could be overcome by the development of high catalase activity which occurs when the organism is trained to high oxygen tensions. The lumen of the gut of the healthy larva is perhaps not completely anaerobic; but the oxygen tension may be low enough to allow growth of $S$. pluton in coccal form and apparently in pure culture. White (1912) described and illustrated the appearance of the mid-gut at an early stage of infection, and stated: 'This parasite (S. pluton) very early takes a position along the peritrophic membrane and just central to it. At this stage of its growth this micro-organism presents in general an appearance of being rod-shaped with a strong tendency to grow in chains.' The initial rod-like appearance in early infection was also noted by Tarr (1937). It seems likely that a rod-like form of $S$. pluton occurs initially at low oxygen tensions but quickly makes the lumen of the gut sufficiently anaerobic to enable the coccal form to develop.

The inhibition of growth of anaerobic cultures of Streptococcus pluton and Bacterium eurydice by citrate or by a high molar ratio of $\mathrm{Na}: \mathrm{K}$ seems to be a feature of lactobacilli (MacLeod \& Snell, 1947, 1948). The effect of sodium is unusually severe on $S$. pluton, however; MacLeod \& Snell observed half maximum growth of various lactobacilli when the molar ratio of $\mathrm{Na}: \mathrm{K}$ was $0 \cdot 81$, but inhibition of $S$. pluton is greater than this when the molar ratio is 3 or less. The molar ratio of $\mathrm{Na}: \mathrm{K}$ in larval blood is about 0.24 (Bishop, Briggs \& Ronzoni, 1925) and in honey it is about 0.26 (Wills, 1956); it is likely that the ratio in the gut of the larva is similar.

The high concentration of phosphate in medium III makes easier the initial isolation of Streptococcus pluton from diseased larvae; it prevents rapid acidification of the medium by Bacterium eurydice. Many difficulties encountered in previous attempts to isolate $S$. pluton were probably largely due to acid production by $B$. eurydice. The success of the isolation by Professor Garrod, of the anaerobic coccus, which was almost certainly S. pluton, on glucose nutrient agar, was probably due in part to the selection of apparently healthy larvae which were often infected with almost pure cultures of this organism.

The vigorous anaerobic growth of Bacterium eurydice in media which contained fructose + glucose suggests that fructose and glucose are used by different metabolic pathways. It may explain the good growth of $B$. eurydice within the larval gut which, although anaerobic or nearly so when it is sup- 
porting a growth of Streptococcus pluton in coccal form, must contain fructose and glucose from the honey which forms part of the larval food.

The inhibition of growth of Streptococcus pluton in pure culture when the $\mathrm{pH}$ value falls below 6.0 and the apparent lack of acid formation suggests that this organism's metabolism is closely adjusted to that of the larva. Bacterium eurydice, however, grows quickly and produces an appreciable quantity of acid with which the larva is probably unable to deal. The $\mathrm{pH}$ value of the mid-gut contents of moribund larvae is $c .4 .0$; it is about 6.3 in healthy larvae or in larvae which are not showing symptoms of disease but which are supporting a rich growth of $S$. pluton.

It seems likely that Bacterium eurydice may be considered the immediate cause of European foul-brood disease but this organism seems able to develop only in larvae which are already infected by Streptococcus pluton. Naturally infected larvae often contain a rich growth of $S$. pluton, apparently in pure culture, before symptoms of European foul-brood disease become apparent. White (1912) pointed out that $B$. eurydice is found in comparatively small numbers at an early stage of the disease and then rapidly increases in number; he found that $S$. pluton was always present first in infected larvae. In larvae from bee colonies infected with pure cultures of $S$. pluton there was an initial growth of this organism but the disease did not appear (Bailey, 1956). When attempts were made to infect bee colonies with pure cultures of $B$. eurydice there seemed to be no growth of these organisms at all.

The contents of the gut of the living larva must resist the growth of many organisms which are swallowed; Streptococcus pluton and Bacterium eurydice, to a lesser degree, must overcome this resistance. $S$. pluton has particularly critical nutritional requirements in anaerobic culture, and these may be linked with a very close adaptation to the environment in the larval gut. B. eurydice has some anaerobic nutritional requirements which are similar to those of $S$. pluton, but they are less critical and this may correspond with the lesser degree of adaptation which $B$. eurydice appears to have developed. It seems possible, therefore, that $S$. pluton decreases the resistance of the gut sufficiently to permit growth of $B$. eurydice. Further lowering of the resistance of the contents of the gut to bacterial growth by the development of $S$. pluton and B. eurydice was indicated when occasional living larvae, with initial symptoms of disease, were found to contain appreciable numbers of $S$. liquefaciens together with $S$. pluton and B. eurydice. All three bacteria were isolated from such larvae. Pure cultures of $S$. liquefaciens fed to healthy larvae did not develop but disappeared. The only other bacterium, commonly associated with European foul-brood disease, which was isolated and identified during this work, was Bacillus alvei. This bacillus was found in the remains of dead larvae only, as might be expected, since it is a strict aerobe.

The opinion of Burri (1943) that Bacterium eurydice changes into Streptococcus pluton, under unknown conditions, seems untenable. Nevertheless, Burri may have succeeded in cultivating $S$. pluton; it may have begun to grow in his initial isolate of $B$. eurydice, in which he was convinced he was growing $S$. pluton, although he was unable to develop subcultures. It seems 
possible that $B$. eurydice provides nutrients which are utilized by $S$. pluton in an otherwise unsatisfactory medium; the consumption of oxygen by $B$. eurydice might be sufficient, even in the aerobic conditions in which Burri incubated his cultures, to enable $S$. pluton to grow slightly within its colonies. The initial isolation of $S$. pluton on medium $\mathbf{I}$, described above, may have been similar to that obtained by Burri, but under more suitable conditions. Such relationships between the two organisms do not seem possible in the larval gut however, as their sequence of appearance is then the reverse of that in artificial culture.

Thanks are expressed to Professor L. P. Garrod (St Bartholomew's Hospital) for his great help in the early stages, to Drs H. G. Thornton, F.R.S. and F. A. Skinner (Soil Microbiology Department, Rothamsted) for helpful discussions, to Mrs E. Booth (née Carlisle) and Mr F. Woodstock for technical assistance, and to Mr R. V. Tipler and Miss Myrtle F. Bray (Imperial Chemical Industries Ltd., Research Station, Jealott's Hill, Berkshire) for the preparation of freeze-dried cultures.

\section{REFERENCES}

BArley, L. (1956). Aetiology of European foul brood; a disease of the larval honeybee. Nature, Lond. 178, 1130.

Bergey's Manual of Determinative Bacteriology (1948). 6th ed. p. 724. Edited by Breed, R. S., Murray, E. G. D. \& Hitchens, A. P. London: Baillière, Tindall \& Cox.

Bishop, G. H., Briggs, A. P. \& Ronzoni, E. (1925). Body fluids of the honeybee larva. II. Chemical constituents of the blood and their osmotic effects. J. biol. Chem. 66, 77.

Burri, R. (1943). Weitere Beobachtungen über Formwandlungen beim Erreger der Sauerbrut der Bienen. Beih. Schweiz. Bienenztg. 1, 209.

Gubler, H. U. (1954). Bakteriologische Untersuchungen über die gutartige Faulbrut der Honigbiene (Apis mellifica L.). Schrweiz. Z. allg. Path. 17, 507.

Lochread, A. G. (1928). The etiology of European foul brood of bees. Science, 67, 159.

MACLEOD, R. A. \& SNELL, E. E. (1947). Some mineral requirements of the lactic acid bacteria. J. biol. Chem. 170, 351.

MacLeod, R. A. \& SNell, E. E. (1948). The effect of related ions on the potassium requirements of lactic acid bacteria. J. biol. Chem. 176, 39 .

Report of the Rothamsted Experimental Station (1954). p. 136.

Steinhaus, E. A. (1949). Principles of Insect Pathology, 1st ed. p. 244. New York: MeGraw-Hill.

TARR, H. L. A. (1937). Studies on European foul brood of bees. III. Further experiments on the production of the disease. Ann. appl. Biol. 24, 614.

White, G. F. (1912). The cause of European foul brood. Dep. Circ. U.S. Dep. Agric. no. 57.

White, G. F. (1920). European foul brood. Dep. Bull. U.S. Dep. Agric. no. 810.

Wilss, A. P. (1956). Sodium and potassium in Australian foods. Aust. J. exp. Biol. med. Sci. 34, 165.

\section{EXPLANATION OF PLATE}

Fig. 1. Streptococcus pluton and Bacterium eurydice from the mid-gut of a living honeybee larva which had symptoms of European foul-brood disease. $\times 2000$.

Fig. 2. S. pluton and B. eurydice, from a mixed anaerobic culture. $\times 2000$.

Fig. 3. S. pluton, cultured on agar in an atmosphere containing $1 \%(\mathrm{v} / \mathrm{v})$ oxygen. $\times 2000$.

Fig. 4. S. pluton, trained to aerobic growth and cultured aerobically on agar. $\times 2000$.

Fig. 5. S. pluton, trained to aerobic growth and cultured in agitated broth. $\times 2000$.

Fig. 6. S. pluton, from anaerobic culture with cell wall stained by Robinow's tannic acid + crystal violet method. $\times 2000$. 
Journal of General Microbiology, Vol. 17, No. 1
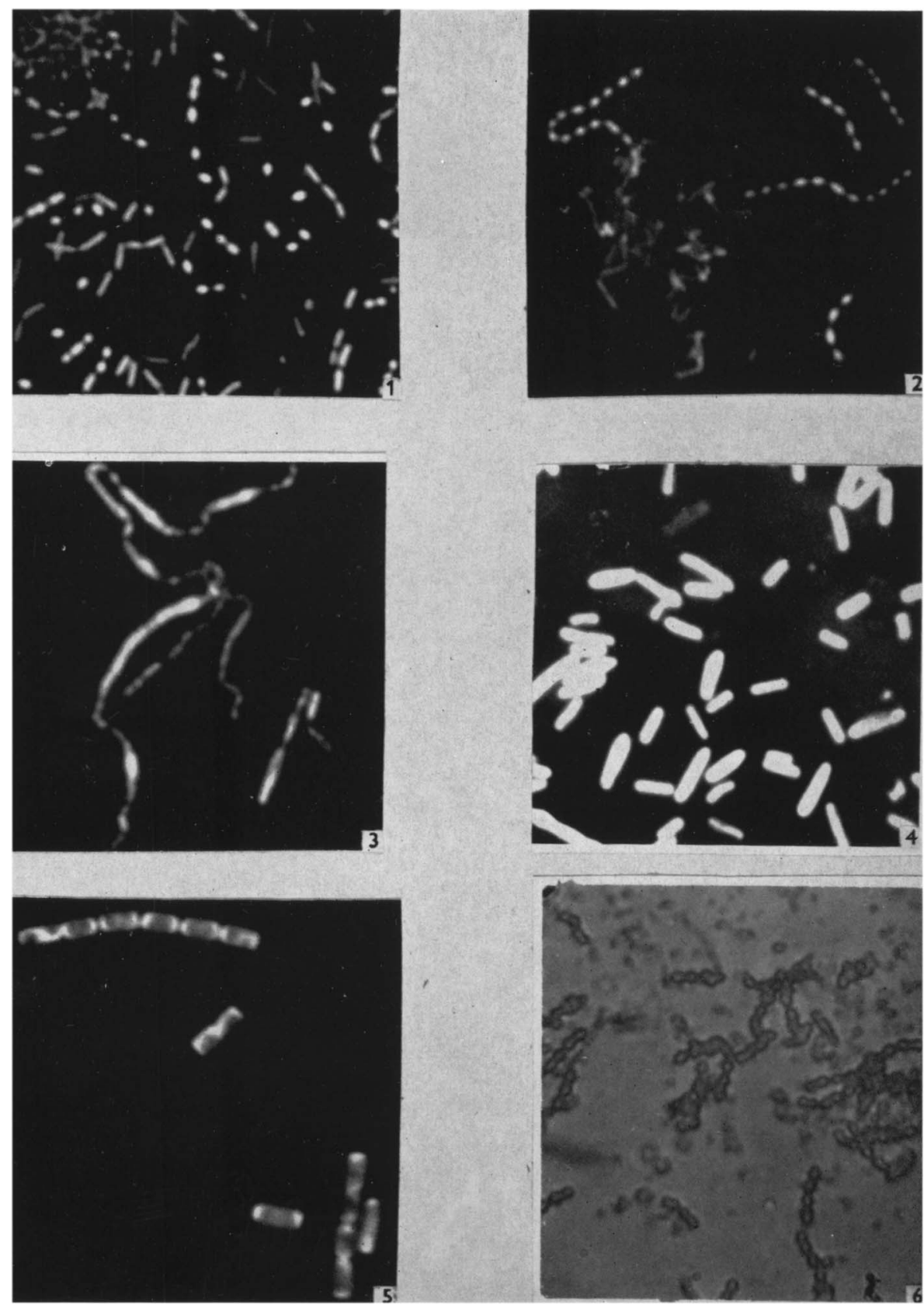

L. Bailey-Isolation of Streptococous pluton. Plate 1 